\title{
The First Language's Impact on L2: Investigating Intralingual and Interlingual Errors
}

\author{
Robert Long ${ }^{1} \&$ Yui Hatcho ${ }^{1}$ \\ ${ }^{1}$ Department of Foreign Languages, Kyushu Institute of Technology, Japan \\ Correspondence: Robert Long, Institute of Liberal Arts, Department of Foreign languages, Kyushu Institute of \\ Technology, Japan. Tel: 81-093-844-3447. E-mail: long@dhs.kyutech.ac.jp
}

Received: August 20, 2018 Accepted: October 13, 2018 Online Published: October 16, 2018

doi: 10.5539/elt.v11n11p115 URL: http://doi.org/10.5539/elt.v11n11p115

\begin{abstract}
This study focused on the grammatical accuracy of Japanese students who were learning English. The database for the errors came from the Japanese University Student Corpus (JUSC) comprising 61 transcripts containing 51,061 words. An inventory, containing 400 errors in context, was taken from this corpus. The first research question related to the most common errors Japanese L2 learners made in spontaneous speech whereas the second question focused on the interpretability and recognition of errors as being intralingual or interlingual. Results showed that the primary errors were articles, verb tense, prepositions, omission, modifier errors, and subject-verb agreement. These results indicate that L1 is a factor in grammatical accuracy. We concluded that this data highlights the need for language teachers to focus on getting students to use the grammatical forms in actual dialogues.
\end{abstract}

Keywords: grammatical accuracy, interlingual and intralingual errors

\section{Introduction}

Despite the trend for more communicative classes, grammar in English education in Japan continues to be given a great deal of attention. TOEIC and Eiken tests have become more popular over the past ten years with students (and teachers) being trained to focus on a wide range of isolated errors and multiple-choice tasks, some of which can be problematic for non-native speakers; however, little attention is paid to the kinds of errors students make in spontaneous discourse. Understanding the nature of these kinds of errors is important insofar that they signal which forms have been acquired and which problems still need to be addressed. As Corder (1967) notes "learners' errors can also provide to the researcher evidence of how language is learned or acquired, what strategies or procedures the learner is employing in the discovery of the language" (p. 167). In short, the issue of acquisition is perhaps a more important issue for language educators so as to prevent the fossilization of errors.

The purpose of this study, therefore, is to identify the most frequent and recurring grammatical errors that Japanese EFL learners made in spontaneous discourse, a topic that has been ignored in most EFL research. Second, it is important to know the role of intralingual and interlingual errors in L2 discourse. Intralingual errors often occur when students do not know the target language (TL) well enough. The students then form generalizations of rules and make utterances that reflect only partial exposure of the TL (Richard, 1974). Intralingual errors essentially occur when the language is being learned. Keshavarz (2004) classified intralingual errors into six categories: (a) overgeneralization, (b) ignorance of rule restrictions, (c) false analogy, (d) hyperextension, (e) hypercorrection, and (f) faulty categorization. For example, overgeneralization occurs with students adding an "s" even to irregular plurals, creating a mutated structure whereas the ignorance of rule restrictions occurs with the learner not obeying the structure of the target language (James, 1998).

Interlingual errors, on the other hand, refer to those errors that are related to cross-linguistic interference, language transfer and to interference (Chelli, 2003). Richards (1974) stated if the learners of a foreign language make a mistake in the target language due to his or her mother tongue, then this is to be termed as an interlingual error. Brown (1980) argued that most learners' errors in the second language result in learners assuming that many rules and forms are similar to their native language. Touchie (1986) also suggested that interlingual errors were caused mainly by mother tongue interference; similarly, another researcher Al-Khresheh (2010) reasoned that interlingual errors are committed by literal translation. Al-Khresheh identified three types: transfers errors, mother tongue interference (which are errors produced in the learner's attempt to discover or try out the 
structures of the TL), and literal translation, errors, which occur with translating sentences or idiomatic expressions. At issue is whether or not educators know the kinds of errors that are being made by students when speaking or writing, and how best to correct them.

\section{Review of Literature}

\subsection{The Nature of Spontaneous Speech}

Spontaneous speech, which can be viewed as a mirror of what students actually know and how they can use it, actually gives an imperfect reflection of students' true proficiency. Spoken language typically has far less grammatical subordination than written language and much more coordination or simple parataxis; this is due to the limitations of short-term memory in both speaker and hearer (Miller \& Weinert, 1998). Both researchers also argue that the short-term memory can hold seven bits (plus or minus two) of information; thus, it is common to find the syntax of oral discourse to be, in general, fragmented phrases. Long's (2016) Japanese Student Corpus Corpus (JUSC) shows numerous examples of such fragmented phrases as well as minimal responses. In the following dialogue, two participants are discussing their background.

F2: Yeah. Yeah.

M2: Study. (Japanese: nandarou.)

F2: Oh. If you got, if you got bad test, uh--

M2: Ah. Yes. $\uparrow$ Yes. $\uparrow$ Of course, Yeah. I mentioned about study. Yes. My family. And so test... It is no problem heh for me. yes

F2: HmM2: I have never $\uparrow$ mentioned about study

M2: Ah: Why? $\uparrow$ Heh heh Why? $\uparrow$

F2: Uh, my father think ah (2.4) woman should cook well.

M2: Ah. Ah.

F2: But I am not good at cooking.

M2: Ah yeah.

F2: So my father scold me, "why?"

M2: Ah heh heh. Don’t $\uparrow$ worry $\uparrow$ about it. $\uparrow$

F2: Why you can not...Yes yes. $\uparrow$

M2: Heee. Hum... What's your hobby?

F2: Oh my hobby is to watch Disney movie.

M2: Disney movie! $\uparrow$

F2: Yeah.

M2: Too many? Many?

F2: Oh $\uparrow$ yeah $\uparrow$.

M2: What's the best $\uparrow$ movie do you like?

F2: Ah my best is Rapunzel.

One means of signaling such relationships between chunks of syntax is played by deictics (Miller, \& Weinert, 1998, p. 22); however, the nature of oral syntax also brings about other kinds of errors due to simplification of a rule, overgeneralization, hypercorrection, faulty teaching, fossilization, avoidance, inadequate learning, and false concepts which are hypothesized (Touchie, 1986). For more on studies of errors types, see (T. S. Huang, 1974; W. H. Huang, 1977; Chiang, 1981; Chen, 1979).

A second issue with spontaneous speech relates to the fossilization of errors. Selinker (1972) discussed this in regards to the learner's native language, interlanguage, and target language. When students are not given adequate feedback concerning their own errors, they become more confident in their usage, causing many errors to become fossilized. Richards (1974) identified seven sources of errors, namely, (a) interference, (b) overgeneralization, (c) performance errors, (d) markers of transitional competence, (e) strategies of communication and assimilation, and (f) successions of approximative systems, and (g) universal hierarchy of 
difficulty.

These sources of errors differed from Stenson (1974) who compiled only three reasons for errors, incomplete acquisition of the target grammar, exigencies of the learning/teaching situation, and errors due to the normal problems of language performance, such as the difficulties, both inter- and intralingual ones, which are expected.

\subsection{Treatment of Errors}

Crosby (2013) noted that while many teachers have questioned the effectiveness of error correction, only a few teachers know about error analysis and its related theories. One of the most important questions in his study was whether or not error correction had an effect on the students' learning achievement, and which specific activity motivated students. Crosby investigated whether or not error correction by the teacher is appreciated by the students, and under what conditions, should self-correction occur. The study involved 57 Japanese university students aged 20 to 22 years old, who are all English majors. The students were separated into two groups. Group A, which had 28 members, was the correction group, and these students regularly corrected each time they made errors. Group B, which had 29 members, was the self-correction group and so were allowed to continue even if they committed errors. The only time errors were corrected was when they specifically asked if they had made an error or if they asked about their global errors and therefore had somehow not been effective in their communication. Crosby's results showed that $29 \%$ of the participants showed appreciation for error correction and that $92 \%$ were motivated to correct themselves when given the autonomy to do so. Moreover, $68 \%$ felt stressed when corrected, and $71 \%$ disclosed that they felt embarrassed when discussions were halted so as to highlight errors. When discussing the issue global errors and correction, students were split when teachers corrected them, with a slight majority preferring not to be corrected, whereas with local errors a two-to-one margin preferred not to be corrected. Crosby concluded error correction is not that effective as a strategy in the classroom.

Pishghadam, Hashemi, and Kermanshahi (2011) proposed that self-correction is more effective when students catch themselves making errors and immediately self-correct the error. Finally, Corder (1967) states that the usefulness of error analysis is evident in three aspects: first to the researcher or linguist, to the language teacher, and to the learners themselves. While analyses of learners' errors provide insights into the nature of language, they provide even more insights into the process of language teaching and learning.

\section{The Study}

\subsection{Rationale}

To better focus material, techniques and tasks in Japanese EFL education, teachers should become familiar with the most common errors Japanese learners are making in their oral interactions. Furthermore, it is important for teachers to know why these errors are occurring: is it because of L1 interference or because of other reasons? Thus, one aim of the present study is to understand how prevalent interlingual errors are in spontaneous speech as compared to intralingual. Some research has been done in regards to the interlingual and intralingual errors; Al-Khresheh, 2010 and Sari, 2016 examined such errors from Jordanian and Indonesian EFL learners. However, research is lacking in regard to Japanese EFL learner's speech. The results of this study can help to orient teachers, letting them understand the processing and application of rules that influence grammatical accuracy. In short, by understanding the patterns and kinds of grammatical errors (intralingual or interlingual) that occur in spontaneous speech, teachers can potentially better provide more meaningful and relevant tasks and tests for their students.

\subsection{Research Questions}

1) What were the most common errors Japanese L2 learners made in this corpus?

2) Regarding the interpretability and recognition of errors, which errors were deemed as interlingual?

\subsection{Corpus}

The Japanese University Student Corpus (JUSC, 2016) (Note 1) was used for data analysis; it contains 61 transcripts with 51,061 words, which were manually transcribed, beginning in March through July 2016. This corpus, which had 400 readily identifiable errors, is used as a source of data for this investigation into grammar. The sentences containing these errors were then put into an inventory for teachers to evaluate. The subjects that created this corpus came from a national university and a municipal university. All of the participants were between the ages of 18 to 21 and had lived in Japan with limited study abroad experiences. Specific test scores, which reflected a similar level of proficiency, were used to select students (see Table 1). Permission was received to videotape and transcribe these interactions. 
Table 1. Scores for lower proficiency students

\begin{tabular}{lllllll}
\hline TOEIC & Eiken & IELTS & TOEFL IBT & TOEFL ITP & TOEFL PBT & TOEFL CBT \\
\hline $440-550$ & Grade 2 & $3.0-4.0$ & $42-55$ & $272-450$ & $463-480$ & $143-157$ \\
\hline
\end{tabular}

\subsection{Procedures}

As Coates (1996) noted discourse is more fluent between friends, thus to eliminate the confounding variable of familiarity, participants had to state that they did not know any of the others in their discourse group. Groups of four students (two males and two females) were then videotaped in one session, with interactions, first taking place between the genders. One male and female were videotaped in two rooms for ten minutes. The second interaction took place with the males switching rooms and starting the second set of gendered discussions. The third session followed with the female-to-female (FF) and male-to-male (MM) interactions. So as to exclusively examine fluency, dysfluency, and grammar instead of communicative competency issues, a discussion format was introduced before the discussion, see Appendix A. The format was based on students first gathering information on a certain topic and talking for around four minutes, and then moving on to shared interests, and then a third item based on cognitive loading, would have subjects answer a personal or social issue. If students finished the three topics before the time allotted, they could move on to the next three on the list. Participants did sign permission forms allowing for their discussions to be videotaped, uploaded to YouTube, and were transcribed. The videos, which are available on YouTube (Note 2), totaled over nine hours and 8.3 minutes (590 minutes) with videos, ranging in length from 6:23 to 14:59 minutes.

\subsection{Data Analysis}

The data were input into Excel and statistics was performed using Xlstat 20.1 (2018) for descriptive statistics, percentages, and t-tests.

\section{Results}

We categorized students' errors in three grammatical classes, (GM1 - articles, nouns, and verbs), type 2 (GM2 pronouns, prepositions, and conjunctions), and type 3 (GM3 - adverbs, adjectives, interjections). As for the first research question, the primary errors were as follows: incorrect use of articles (381), the incorrect verb tense or form (162), the incorrect use of prepositions (158), the omission of verbs (152), modifier error (111), and incorrect subject-verb agreement (76). Regarding other kinds of errors, the misuse of plurals, deletion of words, and wording/rephrasing were the most common mistakes.

As for the second research question concerning intralingual and interlingual errors, $35 \%$ of the 400 errors were deemed as being intralingual [ 859 responses], 51\% were seen as interlingual [1233 responses], and 12.5\% were undetermined [301 responses]. High agreement was noted with teachers categorizing the misuse of articles, plurals, subject-verb agreement, and prepositions as being interlingual due to the grammar of Japanese.

\section{Discussion}

Concerning the types of errors that Japanese EFL learners often make, the data confirm the research and experience of many educators, e.g. (Bryant, 1984) that articles, verb tense, prepositions, modifiers, and subject-verb agreement are the most frequent errors made by Japanese EFL learners. Further research should be conducted on other particular grammatical forms and with more raters. Nonetheless, it was clear that many of these errors were being repeated dozens of times; this should call into question traditional grammar methods that focus on one or two isolated forms in one chapter. Instead, educators should focus on the most common errors in each class and throughout the course, paying attention to a variety of contexts, and increasing levels of complexity. By using grammar strands and clusters (Byrd, 1997), some mastery might be attained which should affect output. Secondly, it is also important for English teachers to realize the impact of L1 on EFL. The first issue concerns how Japanese nouns do not change forms regarding plurals and do not take articles, thus in impromptu speeches, students are likely to forget to make the appropriate changes. Likewise, prepositions in English, like particles in Japanese, take a great deal of time to understand insofar that many are related to idiomatic usage.

We concluded that this data highlights the need for English teachers to focus on verb usage and forms as they occur in actual dialogues. We also recommend that teachers should try introducing more vocabulary, and more auditory exercises such as overlapping and shadowing (repeating words as they are said and after they are said) in order to acquaint students with more standardized usage. 


\section{Conclusion}

The analysis shows that $\mathrm{L} 1$ is more of a factor than many EFL teachers realize, and thus, this information should be highlighted to students as to how their L1 might be impacting their L2. Furthermore, it was learned that specific errors pose particular problems for Japanese EFL learners such as articles, incorrect verb tense and use of prepositions as well as subject-verb agreement among others, thus, educators need to focus on getting students to use the grammatical forms in ever increasing complexity and in various kinds of interactions in order for EFL students to truly master these grammatical forms. Secondly, educators need to understand and use error analysis that is based on actual Japanese EFL usage to address learners' actual grammatical issues that are problematic. Knowledge does not necessarily reflect awareness and impact usage of accurate language forms. In short, it is time to get students to focus on how they should use grammar in their speech and writing instead of just learning about the correct usage of these forms.

\section{Acknowledgments}

This research is supported by the Grant-in-Aid for Scientific Research (KAKENHI) of the Ministry of Education, Culture, Sports, Science, and Technology in Japan (No. 15K02788). I also want to acknowledge the valuable feedback from the reviewers on this manuscript and the insights, and to the ELT editors.

\section{References}

Al-Khresheh, M. H. (2010). Interlingual interference in the English language word order structure of Jordanian EFL learners. European Journal of Social Sciences, 16(1), 105-116.

Brown, H. D. (1980). Principles of language learning and teaching. New Jersey: Prentice Hall Inc.

Bryant, W. (1984). Typical errors in English made by Japanese ESL students. JALT Journal, 6, 1-18.

Byrd. P. (1997). Grammar FROM context: Re-thinking the teaching of grammar at various proficiency levels. The Language Teacher, 21(12). Retrieved from: http://jalt-publications.org/old_tlt/files/97/dec/byrd.html

Chelli, S. (2013). Interlingual and intralingual errors in the use of preposition and articles. Retrieved from http://dspace.univ-biskra.dz:8080/jspui/bitstream/123456789/3571/1/Interlingual\%20or\%20Intralingal\%20 Errors\%20in\%20the\%20Use\%20of\%20Preposition.pdf

Chen, C. (1979). An error analysis of English compositions written by Chinese students in Taiwan. (Unpublished Ph.D. dissertation, the University of Texas at Austin).

Coates, J. (1996). Women talk: Conversations between women friends. Oxford, England: Blackwell.

Chiang, T. (1981). Error analysis: A study of errors made in written English by Chinese learners. (Unpublished M.A. thesis, NTNU).

Corder, S. (1967). The significance of learners' errors. IRAL, 5(4), 161-170.

Crosby, R. (2013). Effectiveness of error correction in a university EFL discussion Class. Gifu Shotoku Gakuen University. Retrieved from https://ci.nii.ac.jp/els/contentscinii_20180426093104.pdf?id=ART0010025559

Huang, T. (1974). A contrastive analysis of the syntactic errors in English made by Chinese students and its implications for the teaching of English syntax to Chinese. (Unpublished Ph.D. dissertation, Southern Illinois University at Carbondale).

Huang, W. (1977). Contrastive analysis, error analysis and teaching English to the Chinese students. (Unpublished M.A. Thesis, NTNU).

James, C. (1998). Errors in language learning and use: Exploring error analysis. New York: Longman.

Keshavarz, M. H. (2013). Contrastive analysis and error analysis. Tehran: Rahnama.

Miller, J., \& Weinert, R. (1998). Spontaneous spoken language: Syntax and discourse. Oxford, Clarendon Press.

Pishghadam, R., Hashemi, M., \& Kermanshahi, P. (2011). Self-correction among Iranian EFL learners: An investigation into their preferences for corrective feedback. Journal of Language Teaching \& Research, 2(5), 957-962. https://doi.org/10.4304/jltr.2.5.957-962

Richards, J. (1974). Error Analysis: Perspective on second language acquisition. London: Longman Group Ltd.

Sari, E. (2016). Interlingual errors and intralingual errors found in narrative text written by EFL students in Lampung. Jurnal Penelitian Humaniora, 17(2), 87-95. https://doi.org/10.23917/humaniora.v17i2.2501

Selinker, L. (1972). Interlanguage. International Review of Applied Linguistics, 10, 209-231. 
Stenson, N. (1974). Induced errors: New frontiers in second language learning. In J. Schumann, \& N. Stenson. (Eds.). Rowley, Mass.: Newbury House Publishers.

Touchie, H. (1986). Second language learning errors their types, causes, and treatment. Proceedings of the JALT Journal, 8(1), 75-80.

XLSTAT. (2018). Addinsoft Inc.

\section{Notes}

Note 1. The corpus can be found at www.genderfluency.com.

Note 2. Gender fluency: YouTube Playlist is entitled "Gender Fluency Basic" (Jose Domingo Cruz).

\section{Appendix A. Abridged Version of Discussion Topics for Corpus}

\section{$1^{\text {st }}$ MM - FF Interactions}

Set 1. A. Share information about classes, hobbies and preferences.

B. Discuss the question: how are you both different?

C. Compare schedules. Who is busier?

Set 2. A. Share as much information about family, friends and major.

B. Discuss the question: what do you both have in common?

C. Compare parents. Whose parents are stricter?

Set 3. A. Share information about your activities, books and movies.

B. Discuss the question: What kind of food do you both dislike?

C. Compare personalities. Who is more social and outgoing?

Set 4. A. Share information about your ideas about 3 dream jobs.

B. Discuss the question: What kind of pets would you like?

C. Compare dreams. How are your future dreams different?

Set 5. A. Share your ideas about your 3 favorite teachers.

B. Discuss the question: what are your four favorite classes?

C. Compare spending habits. Who is a saver or a spender?

Set 6. A. Share information about trips, clubs, and food.

B. Discuss the question: What are your four favorite movies?

C. Compare histories. What was your favorite children's book? 


\section{$2^{\text {nd }} \mathbf{M M}-\mathrm{FF}$ interactions}

Set 1. A. Share information about what you like to buy this year.

B. Discuss the question: do you buy similar items and products?

C. Compare viewing habits. Who has watched more anime?

Set 2. A. Share 3 events you have heard on the news.

B. Discuss the question: what do like watching on TV?

C. Compare viewing habits. Who watches more TV?

Set 3. A. Share information about sports you like or have done.

B. Discuss the question: What kind of sports are the dullest?

C. Compare personalities. Who is more active?

Set 4. A. Share information about current events. What's new?

B. Discuss the question: Who keeps the most up-to-date?

C. Compare interests. Who has more "interests" regarding news?

Set 5. A. Share your ideas about how you have changed in 5 years.

B. Discuss the question: Who has had more problems in life?

C. Compare musical tastes. Which groups do you both dislike?

Set 6. A. Share information about your most important memories.

B. Discuss the question: What was your most important event?

C. Compare past family and school trips. Who saw more of Japan or the world?

\section{Copyrights}

Copyright for this article is retained by the author(s), with first publication rights granted to the journal.

This is an open-access article distributed under the terms and conditions of the Creative Commons Attribution license (http://creativecommons.org/licenses/by/4.0/). 